\title{
Brown's Regional Anesthesia Review - 1st Edition
}

\author{
Ehab Fharag, Loran Mounir-Soliman. Elsevier, 2016, \$111.00, paperback, 192 pages. \\ ISBN 9780323400565
}

\author{
Ariane Clairoux, MD, FRCPC (1)
}

Received: 17 February 2017/Revised: 29 March 2017/Accepted: 11 April 2017/Published online: 19 April 2017

(C) Canadian Anesthesiologists' Society 2017

With the widespread use of ultrasonography in regional anesthesia, novel blocks and techniques are regularly described in the literature. These dynamic, often complex descriptions may be well supplemented with images and videos. Indeed, websites, blogs, and social media have become immediate educational resources for regional anesthesia. For some of the fundamentals of regional anesthesia, however, such as anatomy and pharmacology, anesthesiologists (including those in training) still turn to textbooks. Brown's Regional Anesthesia Review can help bridge the gap between traditional textbooks and webrelated learning platforms in this dynamic, fast-paced educational environment.

Brown's Regional Anesthesia Review is composed of questions and answers based on the last edition of Brown's Atlas of Regional Anesthesia. It contains 450 multiplechoice questions and two practice examinations divided into 20 well-organized, short chapters. The Review covers the basics of regional anesthesia, including the pharmacology of local anesthetics, local anesthetic systemic toxicity, upper and lower limb blocks, and transverse abdominis plane blocks. It also covers moreadvanced areas of regional anesthesia, such as the quadratus lumborum block, suprascapular nerve block, and obturator nerve block. Regional anesthesia techniques in children are described as well.

The chapters are of sufficient length to address each subject thoroughly without being redundant, making the Review an easy read. Thorough explanations are provided not only to validate the correct answers but also to

A. Clairoux, MD, FRCPC ( $\square)$

University of Montreal, Montreal, QC, Canada

e-mail: clairouxariane@gmail.com invalidate the wrong ones. These in-depth explanations are a key feature of this book. They help readers consolidate their learning while broadening their knowledge. The wide coverage of so many aspects of regional anesthesia makes this book appealing to regional anesthesia practitioners at different skill levels.

Most aspects of regional anesthesia are covered, from anatomy and block techniques to ultrasonography. Selected core regional anesthesia concepts are repeated from one chapter to another, facilitating knowledge retention. The variety of questions is good in terms of cognitive complexity, from the obvious to the more complex. The level of complexity also varies in regard to the chapter's subject. For example, the infraclavicular block review chapter is well rounded and suitable for beginners, whereas the quadratus lumborum block chapter contains more complex questions that may be more suited to regional anesthesia experts. The clinical cases presented have good potential for transfer and generalizability to everyday regional anesthesia practice.

Although the book has many strengths, there are some areas for improvement. As is common to many multiauthored books, the quality and quantity of the questions and answers vary greatly from chapter to chapter (and from author to author). Even within a given chapter, the answers to certain questions could be found in the multiple-choice options of the previous questions, often defeating the learning objective of the question. Thus, more consistency, especially in the answers, would be welcome.

The same comment applies to the ultrasound images in some of the questions. Some authors have provided ultrasound images without markers that are often necessary to interpret a static image. For example, the images for the quadratus lumborum block and the 
paravertebral block in the transverse approach - which are expert blocks whose images are difficult to obtain - require markers to allow interpretation. In contrast, the diagrams are well chosen and are an appropriate addition to the content of the chapter.

An electronic version of the book is available on the Expert Consult website (https://expertconsult.inkling.com) and the Inkling app (https://www.inkling.com). The web and app contents are exactly as they are in the book, but they also feature helpful, user-friendly, interactive quizzes. Indeed, these quizzes are well constructed as the correct answer is shown only when the user checks for it. Notably, the images in the electronic version are the same as in the printed version. More interactive questions with images and the use of video material would be appreciated.

Overall, Brown's Regional Anesthesia Review is an excellent review book. Its format of short, well-organized chapters with accompanying questions (and informative answers) creates a dynamic educational forum. Despite minor imperfections in this first edition, the book is a valuable tool for anesthesia providers who are new to regional anesthesia as well as to those occasional practitioners who want to review or maintain their knowledge of regional anesthesia. It is also an excellent educational instrument for regional anesthesia experts, especially in a field where textbooks usually lack up-todate electronic educational tools.

Conflicts of interest None declared.

Editorial responsibility This submission was handled by Dr. Hilary P. Grocott, Editor-in-Chief, Canadian Journal of Anesthesia. 